ORIGINAL ARTICLE

\title{
Improved neurosensory outcome at 8 years of age of extremely low birthweight children born in Victoria over three distinct eras
}

\author{
L W Doyle, P J Anderson, and the Victorian Infant Collaborative Study Group*
}

Arch Dis Child Fetal Neonatal Ed 2005;90:F484-F488. doi: 10.1136/adc.2004.063362

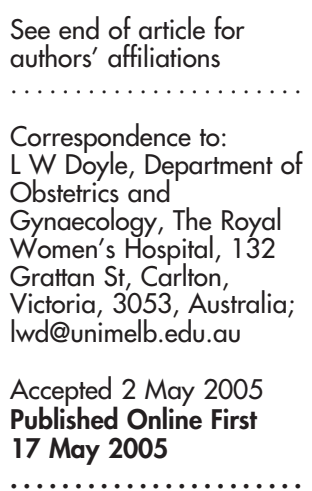

\begin{abstract}
Aim: To determine neurosensory outcome at 8 years of age of extremely low birthweight (ELBW) children born in the 1990s, how it varies with birth weight, and how it compares with ELBW children born in the 1980 s and 1970s.

Methods: Subjects were born in the state of Victoria during 1991-92 and comprised 224 of 241 consecutive survivors with a birth weight of 500-999 g, and 223 of 262 normal birthweight (NBW) controls who had been randomly selected at birth. The comparison cohorts from earlier eras comprised 87 of 89 consecutive ELBW survivors born in 1979-80, 206 of 212 consecutive ELBW survivors born in 1985-87, and 51 of 60 randomly selected NBW survivors born in 1981-82. Survivors were assessed for neurological impairments (cerebral palsy, blindness, deafness, intellectual impairment) and disabilities at 8 years of age by paediatricians and psychologists blinded to perinatal details.

Results: For the 1991-92 cohorts, the rate of neurosensory disability was substantially higher in ELBW children compared with NBW controls $(p<0.0001)$. Within the ELBW group, neurosensory disability was more prevalent in children with a birth weight of $<750 \mathrm{~g}$ compared with a birth weight of 750-999 $\mathrm{g}$ $(p=0.024)$. Disability rates were lower in the 1991-92 ELBW cohort compared with the ELBW cohort born in 1979-80 ( $p=0.046)$.

Conclusions: Neurosensory disability rates at school age were more common in ELBW children born in the 1990s compared with NBW controls, and were significantly more common in the 500-749 g birthweight subgroup, but have improved compared with ELBW children born in earlier eras.
\end{abstract}

\section{METHODS}

\section{Births 1991-92: ELBW and NBW}

The ELBW cohort born between January 1, 1991 and December 31, 1992 comprised 241 survivors to 8 years of age out of 429 consecutive live births with birth weights of 500-999 g in the state of Victoria, Australia, a survival rate of $56.2 \%$. The NBW cohort comprised 265 randomly selected children of birth weight of $>2499 \mathrm{~g}$ born in one of the three level III perinatal centres in Victoria, 262 of whom survived to 8 years of age. Controls were born on the expected date of birth of an ELBW child and matched for gender, the mother's country of birth (English speaking or not), and health insurance status (private health insurance or not). All children were enrolled in the newborn period in a prospective longitudinal study of growth and development throughout childhood; outcomes at 2 and 5 years of age for these children have been reported. ${ }^{7}{ }^{8}$ Written informed consent was obtained from parents of NBW children. Follow up was considered routine clinical care for the ELBW/very preterm children. The Research and Ethics Committees of the Royal Women's Hospital, Melbourne, approved these follow up studies.

Survivors were assessed at 8 years of age by paediatricians and psychologists blinded to perinatal details, predominantly in specialised follow up clinics, although a few were tested at school or home if they could not attend the clinics. Contact was maintained with families by nurse coordinators at each

Abbreviations: $95 \% \mathrm{Cl}, 95 \%$ confidence interval; $\mathrm{CP}$, cerebral palsy; ELBW, extremely low birthweight; NBW, normal birthweight; RCT, randomised controlled trial; SD, standard deviation; WISC-III, Wechsler Intelligence Scale for Children - Third Edition; WISC-R, Wechsler Intelligence Scale for Children - Revised neurosensory outcome with earlier ELBW cohorts born in the same region. 
of the three main testing sites; contact included annual greeting cards, and parents were encouraged to notify changes of contact. There were nine different paediatricians and four different psychologists who assessed the children in all three cohorts. As each new paediatrician or psychologist joined the assessment teams, the current members taught them until their performance was considered satisfactory. There was, however, no formal testing of agreement or reliability.

Impairments included $\mathrm{CP}$, blindness, deafness, and intellectual impairment (IQ $<-1$ standard deviation (SD) relative to the mean and SD for NBW controls). Cognitive ability was assessed using the Wechsler Intelligence Scale for Children Third Edition (WISC-III). ${ }^{9}$ Some children with significant neurosensory impairments were not able to complete the WISC-III because of severe intellectual impairment and were assigned an IQ of -4 , equivalent to a score of 40 for a mean of 100 and SD of 15. Severe disability comprised severe CP (child not walking), blindness (visual acuity $<6 / 60$ in the better eye), or an IQ $<-3 \mathrm{SD}$; moderate disability comprised moderate CP (walking with considerable difficulty, with or without appliances), deafness (requiring hearing aids or worse), or an IQ from -3 SD to $<-2$ SD; mild disability comprised mild CP (walking with minimal limitation), or an IQ from -2 SD to $<-1$ SD.

\section{ELBW births in earlier eras: $1979-80$ and $1985-87$}

Previous regional cohorts of ELBW children had been born in 1979-80 and in 1985-87. The 1979-80 ELBW cohort comprised 89 consecutive survivors to 8 years of age out of 351 live births, a survival rate of $25.4 \%$. Their outcome at 8 years of age was initially reported in 1991. ${ }^{10}$ They had been assessed by techniques similar to those described for the 1991-92 cohorts, but cognition was assessed with the previous version of the WISC, the Wechsler Intelligence Scale for Children - Revised (WISC-R). ${ }^{11}$ As the initial report at 8 years of age did not compare cognition with contemporaneous NBW controls, we re-evaluated their cognitive test scores relative to a randomly selected cohort of $60 \mathrm{NBW}$ children born in one of the level III maternity hospitals in the state in 1981-82.

The 1985-87 ELBW cohort comprised 212 consecutive survivors to 8 years of age from 560 live births, a survival rate of $37.9 \%$. Their outcome at 2 and 5 years of age has been previously reported..$^{12}{ }^{13}$ Their outcome at 8 years of age was assessed using techniques identical to the 1991-92 cohorts, including the WISC-III. We did not, however, have a contemporaneous NBW comparison group, so we used the results of the NBW children born in 1991-92.

\section{Statistical analyses}

The initial comparison of interest was between the ELBW cohort and the NBW controls born in 1991-92. We then compared outcomes within ELBW children alone born in the three eras 1979-80, 1985-87, and 1991-92. Within the ELBW cohorts we contrasted the outcome between the smallest (birth weight 500-749 g) survivors and their slightly heavier (birth weight 750-999 g) counterparts.

Data were analysed by SPSS for Windows, version 12.0.2 (SPSS, Chicago, IL). Between group differences for dichotomous outcome data were analysed by $\chi^{2}$ analysis, or by $\chi^{2}$ for linear trend, and for continuous data by $t$ test, computing mean differences and 95\% confidence intervals (95\% CIs).

\section{RESULTS}

\section{1-92 cohorts}

The follow up rate at 8 years of age for the 1991-92 ELBW cohort was $92.9 \%(224 / 241)$, and $85.1 \%$ (223/262) for the 1991-92 NBW cohort. The mean (SD) age of assessment was
8.7 (0.4) years in the ELBW cohort, and $8.9(0.4)$ years in the NBW cohort. Of the 17 ELBW children not assessed at 8 years of age, four were lost to follow up, nine refused, and four were inaccessible, usually living in another country. Of the 17 ELBW children, 14 had been assessed earlier in childhood: two (14.3\%) had severe disability, three (21.4\%) had moderate disability, three $(21.4 \%)$ had mild disability, and six $(42.9 \%)$ were non-disabled. Of the $39 \mathrm{NBW}$ children not assessed at 8 years of age, 22 were lost to follow up, 13 refused, and four were inaccessible. Of the 39 NBW children, 22 had been assessed earlier in childhood: none had severe disability, one $(4.5 \%)$ had moderate disability, two $(9.0 \%)$ had mild disability, and 19 (86.4\%) were non-disabled. Two NBW children were assessed at 8 years of age in another state but did not have cognitive testing.

At 8 years of age, $28(12.5 \%)$ children in the ELBW cohort exhibited significant neurosensory impairments: three were blind, three were deaf and required hearing aids, and 24 had CP (two of whom were also blind) (table 1). Of those diagnosed with CP, 12 children were classified as mild, four as moderate, and eight as severe. In contrast, only one child in the NBW cohort was diagnosed with CP $(p<0.001)$. The full scale IQ for the 209 ELBW children able to be tested was significantly lower than in the 220 NBW children tested (mean difference $-10.0,95 \%$ CI -12.8 to -7.1 ; table 1 ). Consistent with this finding, the rate of intellectual impairment was significantly higher in the ELBW group compared with the NBW group (table 1).

\section{Comparison with earlier ELBW cohorts}

The follow up rates at age 8 years were 98\% (87/89) for the 1979-80 ELBW cohort, and 97\% (206/212) for the 1985-87 ELBW cohort. Table 2 lists the rates of neurosensory impairments for the ELBW cohorts over the three distinct eras. The rates of $\mathrm{CP}$ and deafness were similar for each ELBW cohort. However, the rate of blindness fell significantly over time from $6.9 \%$ in $1979-80$ to $1.1 \%$ in 1991-92. Mean IQ scores in those able to be tested were similar, but were not compared statistically as the IQ test was not identical for each cohort. While the rate of intellectual impairment decreased marginally from 1979-80 to 1991-92, the severity of impairment was not significantly different in ELBW survivors in any pairwise comparison between eras.

Table 1 Neurological impairments at 8 years of age for the 1991-92 cohorts

\begin{tabular}{|c|c|c|}
\hline & ELBW, $n=224$ & NBW, $n=223$ \\
\hline Cerebral palsy, n (\%) & $24(10.7)$ & $1(0.4)^{*}$ \\
\hline \multicolumn{3}{|l|}{ Cerebral palsy, severity } \\
\hline Nil, n (\%) & 200 (89.3) & $222(99.6) \dagger$ \\
\hline Mild, n (\%) & $12(5.4)$ & $0(0)$ \\
\hline Moderate, n (\%) & $4(1.8)$ & $1(0.4)$ \\
\hline Severe, n (\%) & $8(3.6)$ & $0(0)$ \\
\hline Blindness, n (\%) & $3(1.3)$ & 0 (0)‡ \\
\hline Deafness, n (\%) & $3(1.3)$ & $0(0) \ddagger$ \\
\hline Full scale $I Q$, mean $(S D)$ & $\begin{array}{l}94.9(15.8) \\
n=209\end{array}$ & $\begin{array}{l}104.9(14.1) \\
n=220 \S\end{array}$ \\
\hline Intellectual impairment, severity & $n=224$ & $\mathrm{n}=2211^{\star *}$ \\
\hline Nil, n (\%) & $131(58.5)$ & $193(87.3)$ \\
\hline Mild, n (\%) & $56(25.0)$ & $19(8.6)$ \\
\hline Moderate, n (\%) & $18(8.0)$ & $5(2.3)$ \\
\hline Severe, $\mathrm{n}(\%)$ & $19(8.5)$ & $4(1.8)$ \\
\hline \multicolumn{3}{|c|}{$\begin{array}{l}\text { ELBW, extremely low birthweight; NBW, normal birthweight. } \\
{ }^{*} \chi^{2}=20.4, p<0.0001 ; \text { tincreasing severity of CP between groups, } \\
\chi^{2} \text { trend }=17.6, p<0.0001 ; \ddagger \chi^{2}=1.3, p=0.25 \text {, not significant; } \S \text { mean } \\
\text { difference }-10.0,95 \% \text { confidence interval }-12.8 \text { to }-7.1, p<0.0001 \text {; } \\
\text { Tincreasing severity of intellectual impairment between groups, } \\
\chi^{2} \text { trend }=38.8, p<0.0001 \text {; }{ }^{* *} \text { two children without cognitive tests } \\
\text { excluded. }\end{array}$} \\
\hline
\end{tabular}


Table 2 Neurological impairments at 8 years of age in regional ELBW cohorts compared over three distinct eras

\begin{tabular}{|c|c|c|c|}
\hline & $1979-80, n=87$ & $1985-87, n=206$ & $1991-92, n=224$ \\
\hline Cerebral palsy, n (\%) & $6(6.9)$ & $16(7.8)$ & $24(10.7)^{*}$ \\
\hline Blindness, $n(\%)$ & $6(6.9)$ & $5(2.5)$ & $3(1.1) \dagger$ \\
\hline Deafness, n (\%) & $4(4.6)$ & $1(0.5)$ & $4(1.5) \ddagger$ \\
\hline Full scale IQ, mean (SD) & $96.3 \S(15.0), n=77$ & $94.2-(16.9), n=192$ & $94.9-(15.8), n=209$ \\
\hline Nil, n (\%) & & & \\
\hline Mill n (1) & $44(50.6)$ & $118(57.3)^{\star \star}$ & 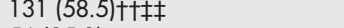 \\
\hline Mild, $\mathrm{n}(\%)$ & $29(33.3)$ & $56(27.2)$ & $56(25.0)$ \\
\hline Moderate, n (\%) & $5(5.7)$ & $21(10.2)$ & $18(8.0)$ \\
\hline Severe, $\mathrm{n}(\%)$ & $9(10.3)$ & $11(5.3)$ & $19(8.5)$ \\
\hline \multicolumn{4}{|c|}{ 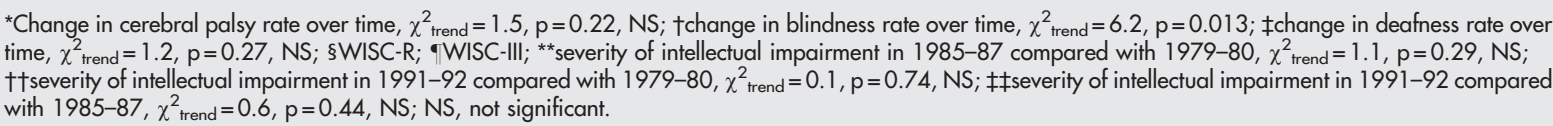 } \\
\hline
\end{tabular}

The severity of neurosensory disability fell significantly in ELBW survivors born in 1985-87 compared with 1979-80 $(\mathrm{p}=0.025)$, and in survivors born in 1991-92 compared with 1979-80 ( $\mathrm{p}=0.046$; table 3$)$. There was no substantial difference in rates of disability between 1985-87 and 199192. The average number of non-disabled children per year increased from 18.5 in 1979-80 to 37.7 in 1985-87, and further to 63 in 1991-92. At the same time, the average number of severely impaired children per year was relatively static, at six in 1979-80, five in 1985-87, and 10 in 1991-92.

Within the 500-749 g birthweight subgroup, the only statistically significant difference found across eras was that survivors born in 1985-87 had substantially lower rates of disability than those born in 1979-80 $(p=0.017)$. On the other hand, within the 750-999 g birthweight subgroup, the only statistically significant difference was that survivors born in 1991-92 had substantially lower rates of disability than those born in 1979-80 $(\mathrm{p}=0.044)$.

In the 1979-80 cohort, the rate of neurosensory disability was worse in those of birth weight 500-749 $\mathrm{g}$ than in those of birth weight 750-999 g, but the difference was not quite statistically significant $\left(\chi^{2}\right.$ test for trend $=3.47, p=0.062$ ). In the 1985-87 ELBW cohort, the rate of neurosensory disability was not significantly different in those of birth weight 500$749 \mathrm{~g}$ from those of birth weight $750-999 \mathrm{~g}$ ( $\chi^{2}$ test for trend $=0.14, p=0.71)$. In the 1991-92 cohort, the rate of neurosensory disability was significantly worse in those of birth weight 500-749 $\mathrm{g}$ than in those of birth weight 750$999 \mathrm{~g}\left(\chi^{2}\right.$ test for trend $\left.=5.1, \mathrm{p}=0.024\right)$.

\section{DISCUSSION}

ELBW children in our study born in the 1990s had higher rates of neurosensory impairments and disabilities than did NBW children at age 8. Compared with ELBW cohorts from earlier eras, the rate of blindness fell substantially over time, as did the rate of overall disability. As the survival rate was so much higher for our 1990s ELBW cohort compared with our earlier regional ELBW cohorts, the absolute number of nondisabled survivors per year increased more than threefold since the late 1970s, far outstripping the relatively unchanged number of survivors per year with severe disability. Within the $250 \mathrm{~g}$ birthweight subgroups, survivors of birth weight 750-999 g had significantly lower rates of disability compared with those of birth weight 500-749 g in the 1991-92 cohort. Differences were not statistically different between birthweight subgroups for the earlier ELBW cohorts, but there were few survivors with birth weights of $<750 \mathrm{~g}$ in these earlier cohorts.

There are other reports of poorer neurological outcome at school age for ELBW or very premature survivors, both before $^{5}{ }^{14}$ and after ${ }^{15}$ the introduction of surfactant. However, we are unaware of any other studies that have reported an

Table 3 Neurological disabilities at 8 years of age in birthweight subgroups in regional ELBW cohorts compared over three distinct eras

\begin{tabular}{|c|c|c|c|c|}
\hline & \multicolumn{4}{|c|}{ Neurosensory disability, $\mathbf{n}(\%)$} \\
\hline & Nil & Mild & Moderate & Severe \\
\hline \multicolumn{5}{|l|}{ 500-999 g birthweight group } \\
\hline $1979-80, n=87$ & $37(42.5)$ & $28(32.2)$ & 10 (11.5) & $12(13.8)$ \\
\hline $1985-87, n=206$ & $113(54.9)$ & $59(28.6)$ & $19(9.2)$ & $15(7.3)$ \\
\hline \multirow{2}{*}{\multicolumn{5}{|c|}{$\begin{array}{l}1791-42, n=224 \\
500-749 \mathrm{q} \text { birthweight group }\end{array}$}} \\
\hline & & & & \\
\hline $1979-80, n=8$ & $2(25.0)$ & $2(25.0)$ & $1(12.5)$ & $3(37.5)$ \\
\hline $1985-87, n=21$ & $11(52.4)$ & $7(33.3)$ & $3(14.3)$ & $0(0.0)$ \\
\hline $1991-92, n=52$ & $21(40.4)$ & $17(32.7)$ & $8(15.4)$ & $6(11.5)$ \\
\hline \multicolumn{5}{|l|}{ 750-999 g birthweight group } \\
\hline $1979-80, n=79$ & 35 (44.3) & $26(32.9)$ & $9(11.4)$ & $9(11.4)$ \\
\hline $1985-87, n=185$ & $102(55.1)$ & $52(28.1)$ & $16(8.6)$ & $15(8.1)$ \\
\hline $1991-92, n=172$ & 105 (61.0) & $39(22.7)$ & $14(8.1)$ & $14(8.1)$ \\
\hline \multicolumn{5}{|c|}{ 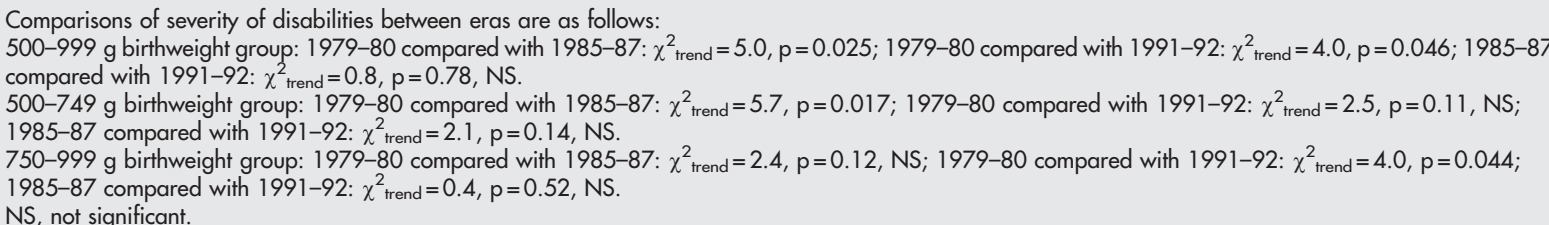 } \\
\hline
\end{tabular}


improvement in neurosensory outcome at school age in ELBW children born within a defined geographical region in the post-surfactant era compared with outcomes within the same region before surfactant was introduced. Moreover, as the extra survivors in the 1991-92 cohort were predominantly in the higher risk birthweight category for adverse neurosensory disability (birth weight 500-749 g) yet considerably more non-disabled children survived compared with earlier cohorts, the improved neurosensory outcome for the 1991-92 cohort represents an even more important clinical improvement.

The strengths of this study are that the ELBW cohorts were geographically determined and hence not subject to referral biases, the follow up rates were high $(>90 \%$ for ELBW cohorts), and the age of assessment was well into school age, by which time ascertainment of neurological impairments and disabilities is more certain than it is in early childhood. The weaknesses of the study include the non-ideal nature of the NBW comparison groups for the earlier ELBW cohorts as they were not exactly contemporaneous. In addition, there were few survivors of birth weight of $<750 \mathrm{~g}$ in the earlier cohorts, reducing the power to find statistically significant differences between the $250 \mathrm{~g}$ birthweight subgroups. Another potential limitation is that the outcomes reflect perinatal practices from a decade or more ago and it may be argued that the results are not relevant to babies in the nursery today. However, this study provides the most accurate data on likely rates of neurological impairments and disabilities at school age in ELBW survivors, until superseded by more contemporary data. We recognise that assessment of children should incorporate outcomes beyond major neurosensory impairments and disabilities, as in this report. We have described elsewhere other outcomes for the 1991-92 children, including executive function ${ }^{16}$ and other cognitive outcomes, ${ }^{17}$ and reports of their behaviour and respiratory function are in progress.

The observation that neurosensory outcome for ELBW survivors improved between the 1970s and the 1980s, but no further in the 1990s, raises the possibility that some of the newer therapies, such as surfactant, although improving survival, might not reduce the rate and severity of neurological impairments in survivors. In support of this reasoning, reviews of the randomised controlled trials (RCTs) of surfactant therapy suggest that long term outcome is, if anything, only marginally improved following this intervention. ${ }^{18}{ }^{19}$ Another explanation might be that other therapies introduced or used more frequently in recent times could have adverse neurological consequences for survivors, for example postnatal steroid therapy to treat or prevent bronchopulmonary dysplasia, ${ }^{20-22}$ that counterbalance any potential gains in outcome by therapies such as surfactant. Whatever the explanation, the higher rates of impairments and disabilities in ELBW survivors relative to NBW controls mean that newer techniques and therapies to improve neurosensory outcome must be sought, preferably through the most efficient study design, the RCT.

In conclusion, neurosensory disability rates at school age remain substantially more common in ELBW children compared with NBW controls, and were significantly more common in children with birth weights of $<750 \mathrm{~g}$. On a positive note, not only are there now more survivors, but there has also been a substantial improvement in neurosensory disability rates at school age in ELBW survivors since the 1970s.

\section{Authors' affiliations}

L W Doyle, P Anderson, Royal Women's Hospital, Melbourne, Australia P Anderson, Murdoch Children's Research Institute, Melbourne,

Australia

L W Doyle, University of Melbourne, Melbourne, Australia

\section{What is already known on this topic}

- ELBW infants are surviving in increasing numbers over the past few decades with rates of neurosensory disability in early childhood that remain high compared with NBW controls

\section{What this study adds}

- Neurosensory disability rates at school age remain substantially more common in ELBW children compared with NBW controls for those born in the 1990s, in the era post-surfactant, and are higher in those of birth weight of $<750 \mathrm{~g}$

- Not only are there now more survivors, but there has also been a substantial improvement in neurosensory impairment and disability rates at school age in ELBW survivors

- The number of non-disabled survivors has increased more than threefold since the late 1970s, whereas the number of severely disabled survivors has remained relatively static

This study was supported in part by a grant from Health and Community Services, Victoria, and Project Grant No. 108702 from the National Health and Medical Research Council, Australia

Competing interests: none declared

*Participants: Convenor: Lex W Doyle, MD, FRACP. Collaborators (in alphabetical order): Peter Anderson, PhD; Catherine Callanan, RN; Elizabeth Carse, FRACP; Dan Casalaz, FRACP; Margaret P Charlton, MEd Psych; Noni Davis, FRACP; Julianne Duff, FRACP; Geoffrey Ford, FRACP; Simon Fraser, FRACP; Marie Hayes, RN; Mary Kaimakamis, BSc; Elaine Kelly, MA; Gillian Opie, FRACP; Andrew Watkins, FRACP; Heather Woods, RN; Victor Yu, MD, FRACP

\section{REFERENCES}

1 Soll RF. Surfactant treatment of the very preterm infant. Biol Neonate 1998;74(Suppl 1):35-42.

2 Doyle LW, and the Victorian Infant Collaborative Study Group. Evaluation of neonatal intensive care for extremely low birth weight infants in Victoria over two decades: I. Effectiveness. Pediatrics 2004;113:505-9.

3 Ornstein M, Ohlsson A, Edmonds J, et al. Neonatal follow-up of very low birthweight/extremely low birthweight infants to school age: a critical overview. Acta Paediatr Scand 1991;80:741-8.

4 Knoches AM, Doyle LW. Long-term outcome of infants born preterm. Baillieres Clin Obstet Gynaecol 1993;7:633-51.

5 Hack M, Taylor HG, Klein N, et al. School-age outcomes in children with birth weights under $750 \mathrm{~g}$. N Engl J Med 1994;331:753-9.

6 Taylor HG, Klein N, Minich NM, et al. Middle-school-age outcomes in children with very low birthweight. Child Dev 2000;71:1495-511.

7 The Victorian Infant Collaborative Study Group. Improved outcome into the 1990s for infants weighing 500-999 g at birth. Arch Dis Child Fetal Neonatal Ed 1997;77:F91-4.

8 The Victorian Infant Collaborative Study Group. Postnatal corticosteroids and sensorineural outcome at 5 years of age. J Paediatr Child Health 2000;36:256-61

9 Wechsler D. Wechsler Intelligence Scale for Children - Third Edition. New York: The Psychological Corporation Harcourt Brace Jovanovich, 1991.

10 The Victorian Infant Collaborative Study Group. Eight-year outcome in infants with birth weight of 500 to 999 grams: continuing regional study of 1979 and 1980 births. J Pediatr 1991;118:761-7.

11 Wechsler D. Wechsler Intelligence Scale for Children - Revised. New York: The Psychological Corporation, 1974.

12 The Victorian Infant Collaborative Study Group. Improvement of outcome for infants of birth weight under $1000 \mathrm{~g}$. Arch Dis Child $1991 ; 66: 765-9$. 
13 The Victorian Infant Collaborative Study Group. Neurosensory outcome at 5 years and extremely low birthweight. Arch Dis Child Fetal Neonatal Ed 1995;73:F143-6.

14 Whiffield MF, Grunau RV, Holsti L. Extremely premature ( $<$ or $=800 \mathrm{~g})$ schoolchildren: multiple areas of hidden disability. Arch Dis Child Fetal Neonatal Ed 1997;77:F85-90.

15 D'Angio CT, Sinkin RA, Stevens TP, et al. Longitudinal, 15-year follow-up of children born at less than 29 weeks' gestation after introduction of surfactant therapy into a region: neurologic, cognitive, and educational outcomes. Pediatrics 2002;110:1094-102.

16 Anderson PJ, Doyle LW, for the Victorian Infant Collaborative Study Group. Executive functioning in school-aged children who were born very preterm or with extremely low birth weight in the 1990s. Pediatrics 2004; 114:50-7.

17 Anderson P, Doyle LW. Neurobehavioral outcomes of school-age children born extremely low birth weight or very preterm in the 1990s. JAMA 2003;289:3264-72
18 Soll RF. Synthetic surfactant for respiratory distress syndrome in preterm infants (Cochrane Review). In: Cochrane Library, Issue 1, 2004. Chichester, UK: John Wiley, 2004.

19 Soll RF. Prophylactic synthetic surfactant for preventing morbidity and mortality in preterm infants (Cochrane Review). In: Cochrane Library, Issue 1, 2004. Chichester, UK: John Wiley, 2004.

20 Halliday HL, Ehrenkranz RA, Doyle LW. Early postnatal (<96 hours) corticosteroids for preventing chronic lung disease in preterm infants (Cochrane Review). In: Cochrane Library, Issue 1, 2004. Chichester, UK: John Wiley, 2004

21 Halliday HL, Ehrenkranz RA, Doyle LW. Moderately early (7-14 days) postnatal corticosteroids for preventing chronic lung disease in preterm infants (Cochrane Review). In: Cochrane Library, Issue 1, 2004. Chichester, UK: John Wiley, 2004.

22 Halliday HL, Ehrenkranz RA, Doyle LW. Delayed (>3 weeks) postnatal corticosteroids for chronic lung disease in preterm infants (Cochrane Review). In: Cochrane Library, Issue 1, 2004. Chichester, UK: John Wiley, 2004.

\section{IMAGES IN NEONATAL MEDICINE}

\section{Watershed infarcts in the full term neonatal brain}

W

tershed infarcts, or parasagittal cerebral injury, were demonstrated in the asphyxiated neonatal brain the late 1970s with the use of technetium scans, ${ }^{1-3}$ but were extremely difficult to visualise in the acute phase in vivo. ${ }^{2}{ }^{4}$

Recently, a full term boy was born after a caesarean section because of mild fetal distress. A cephalic version was performed at 38 weeks, but the pregnancy was otherwise uneventful. Umbilical arterial $\mathrm{pH}$ was 7.31, and Apgar scores were 8 and 9 at one and five minutes respectively. Birth weight was $3160 \mathrm{~g}$. Twenty three hours after birth the baby developed left sided seizures with secondary generalisation. Seizures were treated effectively with phenobarbital, lidocaine, and midazolam. No infection, anaemia, or hypotension were demonstrated. Fifty six hours after birth, magnetic resonance imaging (MRI) was performed, which showed parasagittal changes (watershed infarcts) with diffusion weighted MRI. The apparent diffusion coefficient of water of these areas was $0.70 \times 10^{-3} / \mathrm{mm}^{2} / \mathrm{s}$. T1 and T2 weighted MRI showed subtle changes of the white matter.

On the 8th day of life the patient was discharged home being fully breast fed. MRI at 3 months showed a slight increase in the frontal cerebrospinal fluid space, with minimal loss of differentiation between grey and white matter (fig 1). Clinical examination at 6 months showed a normal early development.

We conclude that diffusion weighted MRI is an excellent technique for detection of watershed infarcts in vivo in neonates. These lesions may be partly reversible, as in our patient, although we expect to see gliosis in these areas in the second year of life. Further use of these MRI techniques and neurodevelopmental follow up will show the functional consequences of these brain lesions.

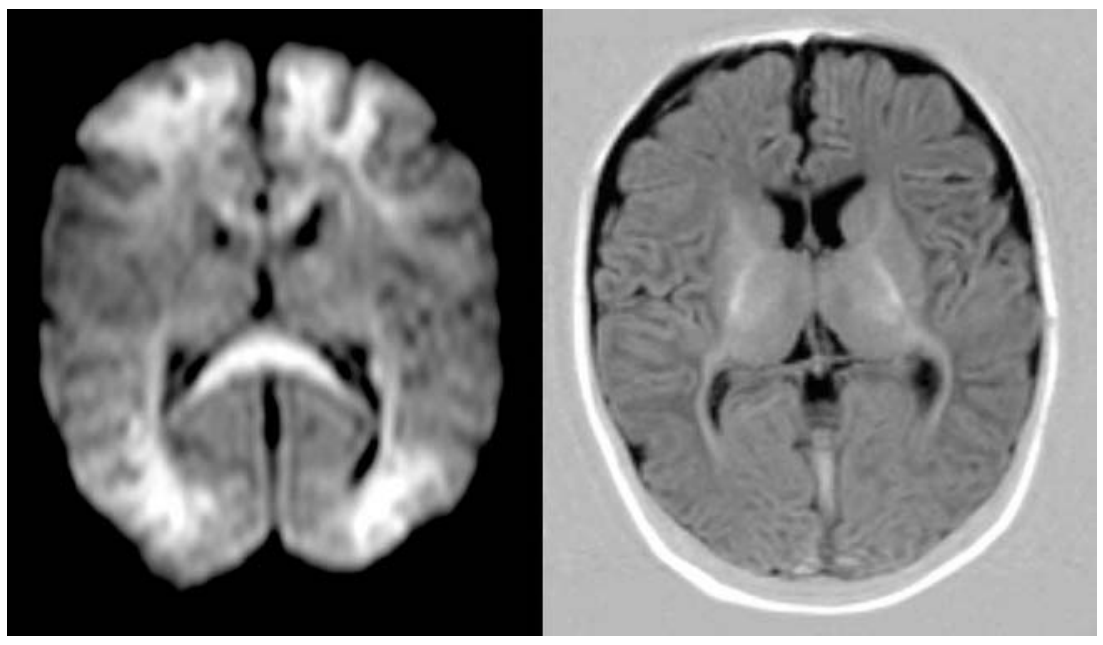

Figure 1 (A) Diffusion weighted magnetic resonance imaging (MRI) scan of the brain of a full term male infant 56 hours after birth, showing parasagittal changes (watershed infarcts); (B) inversion recovery $M R I$ scan at three months.

F Groenendaal, L S de Vries

Wilhelmina Children's Hospital/University Medical Center Utrecht, Netherlands

Correspondence to: Dr Groenendaal, Department of Neonatology, Wilhelmina Children's Hospital, UMC Utrecht, Room KE 04.123.1, Lundlaan 6, Utrecht 3584 EA, Netherlands;

f.groenendaal@wkz.azu.nl

Competing interests: none declared

\section{REFERENCES}

1 Volpe JJ, Pasternak JF. Parasagittal cerebral injury in neonatal hypoxic-ischemic encephalopathy: clinical and neuroradiologic features. J Pediatr 1977;91:472-6.

2 Volpe JJ, Herscovitch P, Perlman JM, et al. Positron emission tomography in the asphyxiated term newborn: parasagittal impairment of cerebral blood flow. Ann Neurol 1985; 17:287-96.

3 O'Brien MJ, Ash JM, Gilday DL. Radionuclide brain scanning in perinatal hypoxia/ischemia. Dev Med Child Neurol 1979:21:161.

4 Flodmark O, Becker LE, Harwood-Nash DC, et al. Correlation between computed tomography and autopsy in premature and full-term neonates that have suffered perinatal asphyxia. Radiology 1980;137:93-103.

5 Coskun A, Lequin M, Segal M, et al. Quantitative analysis of MR images in asphyxiated neonates: correlation with neurodevelopmental outcome. AJNR Am J Neuroradiol 2001;22:400-5. 